\title{
O IMPERATIVO EM LIVROS DIDÁTICOS DE LÍNGUA PORTUGUESA: a distância entre pesquisa e ensino
}

\author{
Márcia Cristina de Brito Rumeu \\ Universidade Federal de Minhas Gerais \\ Luiz Fernando de Carvalho \\ Universidade Federal de Minas Gerais
}

RESUMO

O objetivo deste artigo é discutir a incorporação dos resultados das pesquisas linguísticas sobre a expressão variável do imperativo nas aulas de língua portuguesa com base na análise de livros didáticos do ensino médio, licenciados pelo Programa Nacional do Livro Didático (PNLD) em suas versões dos anos de 2015 e de 2018. Trazemos à cena a perspectiva da tradição em relação ao imperativo e alguns dos resultados das pesquisas linguísticas acerca do estatuto variável do imperativo gramatical no português brasileiro. Assim sendo, constatamos que a abordagem do imperativo se dá conservadoramente em consonância com os preceitos da tradição gramatical, reforçando-se tão somente o seu valor ilocucionário para a construção do sentido.

PALAVRAS-CHAVE: imperativo gramatical; variação pronominal; livros didáticos.

\section{Considerações iniciais}

A reorganização do quadro pronominal do português brasileiro (doravante $\mathrm{PB}$ ) acionada pela inserção do você repercutiu na configuração do imperativo de $2^{\mathrm{a}}$ pessoa do singular (doravante 2SG), cf. Lopes (2007), Lopes e Cavalcante (2012), Rumeu (2013), Rumeu (2016), DINIZ (2018). 
A identidade semântica entre tu e você como formas pronominais de referência ao sujeito de $2 \mathrm{SG}$ alcançou as construções imperativas associadas ao indicativo em contexto de você-sujeito como evidência do imperativo abrasileirado ("Vem pra Caixa você também. Vem"), conferir em Paredes Silva (2000). Neste trabalho, assumimos, à luz de Lopes (2007) e de Lopes e Cavalcante (2012), que uma das consequências da entrada do você no quadro pronominal do PB é a alternância entre as formas verbais de indicativo e de subjuntivo relacionadas às formas pronominais $t u$ e você também nas estruturas de imperativo de $2 \mathrm{SG}$ (vem tu/vem você, venha você).

Tendo em vista o inovador imperativo abrasileirado (vem você) cujas pistas históricas já se deixaram evidenciar em sincronias passadas (fins do século XIX), cf. Rumeu (2016), Silva (2017) e Diniz (2018), pretendemos averiguar até que ponto os resultados das pesquisas linguísticas alcançaram os materiais didáticos e, portanto, chegaram às salas de aulas brasileiras. Este trabalho segue na trilha das análises de Lopes (2012) e de Marcotulio et.al. (2015) acerca do descompasso entre pesquisa e ensino em relação à reorganização dos quadros dos pronomes pessoais e possessivos do PB, respectivamente.

Para discutirmos a relação entre pesquisa e ensino, organizamos este texto em cinco seções. A partir das breves considerações iniciais sobre a reorganização do quadro pronominal do $\mathrm{PB}$ e a sua consequente repercussão em relação à expressão gramatical do imperativo de $2 \mathrm{SG}$, retomamos, na seção 2 , a perspectiva tradicional. Uma vez exposto o imperativo à luz da norma padrão, sintetizamos, na seção 3 , alguns dos principais resultados das análises sociolinguísticas contemporâneas. $\mathrm{Na}$ seção 4, analisamos a abordagem do imperativo concedida por quinze livros didáticos de Língua Portuguesa do Ensino Médio em relação à sua definição, à sua composição morfológica (subseção 4.1) e à sua expressão gramatical variável (subseção 4.2) no PB atual. Por fim, fechamos o texto, na seção 5, com algumas generalizações sobre a relação entre a expressão gramatical do imperativo amplamente discutida no âmbito das análises sociolinguísticas do PB e a sua repercussão nas salas de aulas.

\section{0 modo imperativo: a visão tradicional.}

Representantes do pensamento tradicional, tais como Cunha e Cintra ([1985] 2007), Rocha Lima ([1972] 2010) e Bechara ([1961] 2009), embasados na língua escrita literária, convergem na prescrição do imperativo como um modo verbal marcado pelo ato ilocutório diretivo (SEAR- 
LE, 1969 citado em FARIA 2006, p. 73-74). Ao reproduzirem, a proposta da tradição gramatical, os gramáticos prescrevem as construções imperativas em suas expressões afirmativa e negativa (quadro 01).

\begin{tabular}{l|l}
\hline IMPERATIVO AFIRMATIVO & IMPERATIVO NEGATIVO \\
\hline- & - \\
canta tu & não cantes tu \\
cante você, o senhor & não cante você, o senhor \\
cantemos nós & não cantemos nós \\
cantai vós & não canteis vós \\
cantem vocês, os senhores & não cantem vocês, os senhores \\
\hline
\end{tabular}

Quadro 01: 0 imperativo no Português, cf. Bechara ([1961] 2009, p. 237).

Para o paradigma de imperativo afirmativo, são prescritas as formas do paradigma de $2^{\text {a }}$ pessoa no indicativo sem a marca formal -s (imperativo verdadeiro: canta (tu), cantai (vós)) e as formas do paradigma de você no subjuntivo (imperativo supletivo: cante (você)). Partindo do pressuposto de que cabe às formas de $2^{\text {a }}$ pessoa do singular e de $2^{\text {a }}$ pessoa do plural (doravante 2PL) a expressão genuína do ato diretivo, peculiar ao modo imperativo por excelência para a expressão de pedidos, ordens, súplicas, assumimos que tão somente as formas de $2 \mathrm{SG}$ e $2 \mathrm{PL}$ reservam formas verbais que lhe são específicas, conferir Bechara ([1961] 2009, p. 237), já que as demais pessoas do imperativo afirmativo são integralmente recolhidas do paradigma de subjuntivo. Em relação ao paradigma do imperativo negativo, observamos na íntegra, por outro lado, a sua pertença ao modo subjuntivo. Ainda que tenhamos consciência de que a norma padrão tenha mesmo de manter-se fiel à reprodução da tradição gramatical, observamos que tão somente a $2 \mathrm{SG}$ reflete o uso de formas alternantes entre formas dos paradigmas de $t u$ e você.

Assim sendo, as questões norteadoras desta análise são as seguintes: (I) Os materiais didáticos reproduziriam os paradigmas de imperativo em conformidade com a norma padrão ou já incorporariam aspectos da norma de uso (CUNHA, 1985) voltadas para o imperativo abrasileirado?; (II) A relação entre a reorganização do sistema pronominal e o estatuto variável das construções imperativas no PB é, de alguma forma, depreendida na exposição do tópico imperativo nos livros didáticos? 


\section{A expressão variável do imperativo de 2SG: o que dizem as pesquisas sociolinguísticas?}

Em consequência da reorganização do sistema pronominal do PB ativada também pela inserção de você para a referência ao sujeito de $2 \mathrm{SG}$, a estruturação das construções imperativas parece passar por uma mudança em progresso, conforme discutido por Scherrer (2007, p. 204). Em outras palavras, a ideia é a de que em virtude de um processo gradual e paulatino de implementação do inovador você no acervo pronominal do PB também foi acionado o imperativo abrasileirado, caracterizado pelas construções imperativas associadas às formas verbais indicativas no contexto de você-sujeito, como ilustramos em (1), propaganda amplamente divulgada em território nacional, e, em (2), trecho de diálogo da revista em quadrinhos Turma da Mônica (SCHERRE, 2004; 2007).

(1) "Vem pra Caixa você também, vem!"

(2) "Faz de conta que você está andando pela rua..."

Com o intuito de comprovarmos não só o estatuto variável do imperativo, mas também a mudança em progresso em relação à inserção do imperativo abrasileirado, trazemos à discussão as considerações de Scherre (2007) e Scherre (2012) acerca das construções imperativas produtivas nas Revistas em Quadrinhos da Turma da Mônica entre os anos de 1970 e 2005 (gráfico 01) e da expressão variável do imperativo no PB falado (gráfico 02).

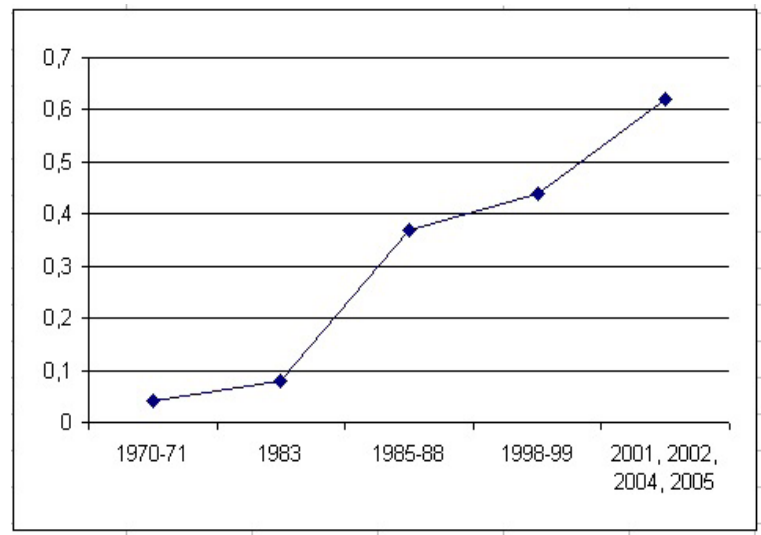

Gráfico 01: 0 imperativo abrasileirado nas revistas em quadrinhos, adaptado dos resultados da tabela 2 de SCHERRE (2007, p. 211) 


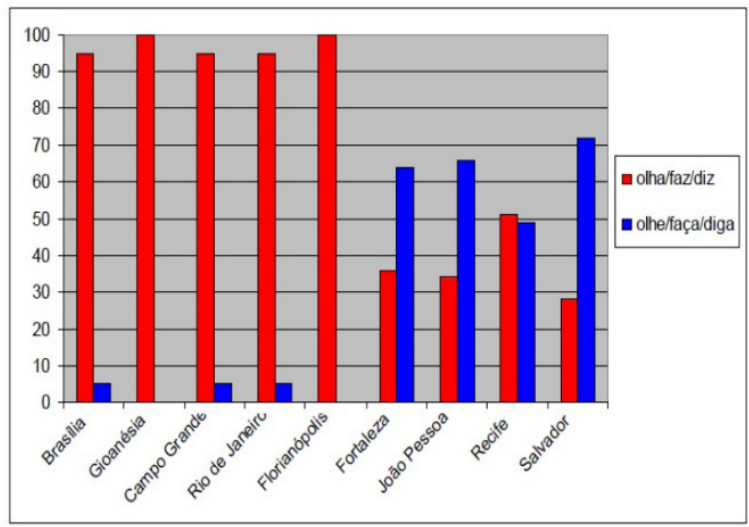

Gráfico 02: Distribuição do imperativo gramatical no eixo geográfico em diálogos de língua falada, cf. SCHERRE (2012).

Ao acompanharmos, no gráfico 01, os índices probabilísticos das construções imperativas associadas ao indicativo em contexto de você, observamos uma gradativa tendência de uso do imperativo abrasileirado no decorrer do tempo $(1970-71 \rightarrow 0,04 ; 1983 \rightarrow 0,08 ; 1985-88 \rightarrow 0,37$; $1998-99 \rightarrow 0,44$ e 2001-05 $\rightarrow$ 0,62). Isso significa interpretarmos o imperativo como um fenômeno cuja expressão mostra-se variável e parece despontar como uma evidência de inserção gradual do imperativo abrasileirado no PB, ou seja, para a convivência de uma forma verbal indicativa (típica do paradigma de $t u$ ) combinada ao você-sujeito com mais força, sobretudo, a partir dos anos 2000 com peso relativo 0,62.

A distribuição dos dados de imperativo por alguns estados brasileiros permite constatarmos, através do gráfico 2, as regiões sul, sudeste e centro-oeste como espaços em que se mostram profícuas as formas verbais indicativas (fala/diz/vai). Em sentido inverso, observamos que, nos estados do nordeste do Brasil, mostram-se produtivas as formas subjuntivas (fale/diga/vá) nas construções imperativas, ainda que, nas cidades do nordeste analisadas (Fortaleza, João Pessoa, Recife e Salvador), os níveis de produtividade das formas indicativas e subjuntivas tenham se mostrado clarividentemente com mais força. Assim sendo, Scherre (2012), à luz do gráfico 2, prevê o delineamento de uma isoglossa. Esses resultados conduzem a interpretação da expressão gramatical do imperativo como 
um fenômeno variável que parece encaixado no tempo e também no espaço. Isso posto, acrescentemos ainda o fato de que se, por um lado, o fenômeno do imperativo abrasileirado evidencia a explícita ausência de concordância entre uma forma verbal no indicativo e o sujeito você (vem você), por outro lado, parece apontar para um processo de variação e mudança linguística no PB abaixo da consciência social (SCHERRE, 2012). Em síntese, o quadro 02 a seguir exposto sistematiza as três possibilidades de configuração do imperativo no PB atual: o imperativo verdadeiro (tu-suj. associado a uma forma verbal no indicativo), o imperativo supletivo (você-suj. associado a uma forma verbal no subjuntivo) e o imperativo abrasileirado (você-suj. associado a uma forma verbal no indicativo).

\begin{tabular}{l|ll}
\hline \multicolumn{3}{l}{ POSSIBILIDADES DE REPRESENTAÇÃO DO IMPERATIVO NO PB } \\
\hline PRONOME-SUJEITO & FORMA VERBAL & CLASSIFICAÇÃO \\
\hline$T u$ & Indicativo & verdadeiro \\
Você & Subjuntivo & supletivo \\
Você & Indicativo & abrasileirado \\
\hline
\end{tabular}

Quadro 2: As possibilidades de representação do imperativo no PB atual.

Tendo em vista o inovadorismo das construções imperativas estruturadas com formas de indicativo em contexto de você-sujeito, ilustramos, de (3) a (7), evidências históricas do imperativo abrasileirado na produção escrita de cariocas cultos marcada pela intimidade das cartas pessoais (familiares, amorosas e de amizade) dos séculos XIX e XX, cf. discutido por Rumeu (2016) e Diniz (2018).

(3) "[...] Pede aDeos minha Filha pela saude de teu Pae. Reconheço que a minha existência é necessaria ao bem dos nossos. [...] sendo provavel que a esta hora já Você tenha recebido.” (JPF. RJ, 16.07.1879.)

(4) “[...] Hoje eu não tenho mais tempo de escrever á Mamãe, por isso você agradece por mim. [...]" (JP. Paris, 15.10.1905.)

(5) [...] penso que estarás desejoso de saber como chegamos [...] depois que acabe Você me avisa por favor [...] Quando já saiba alguma noticia que me interessa sobre Você me avisa, pois sabe o gozo que terei. [...] (MRPCAM. Buenos Aires,. 13.02.1933.)

(6) "Murilo: [...] Como naturalmente ele vai precisar de saber sempre noticias da sua filhinha que vai ficar aí, você combina com ele 
esse negocio do telefone da Folha de Minas de noite [...]" (MR. RJ, 09.10.1941.)

(7) "[...] Para o Gulhermino você repara que eu mandei na lista manuscrita. [...]" (MR. RJ, 26.10.1947.)

Ainda que, de um modo geral, a preferência carioca tenha sido pelas construções imperativas supletivas em $60 \%$ dos dados (442/732), Diniz (2018) descreve a questão do imperativo abrasileirado em sincronias passadas do PB (séculos XIX e XX), tendo em vista os índices percentual e probabilístico de $45 \%$ ( 85 oco) e 0.464 , respectivamente, em cartas

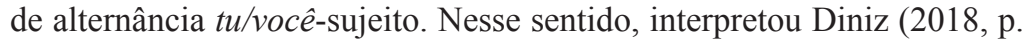
142) "o fato de o contexto de alternância tu/você-suj. (cartas mistas) ter se mostrado como um condicionamento que tende moderadamente a impulsionar as construções imperativas associadas ao indicativo”. A peculiaridade desses dados é potencializada justamente pelo caráter misto das cartas (tu/você) que marcadas pelo você-sujeito selecionam, em $45 \%$ dos dados (85 ocorrências), o imperativo abrasileirado.

Em suma, considerando os estudos de Scherre $(2004,2007,2012)$ e de Diniz (2018), que, por sua vez, dialogam com os resultados alcançados por Rumeu (2016) e SILVA (2017) em análises de sincronias passadas do $\mathrm{PB}$, é clarividente a expressão variável do imperativo de $2 \mathrm{SG}$, apontando inclusive para o favorecimento das construções imperativas associadas ao indicativo em vigência no $\mathrm{PB}$ e pistas desse inovadorismo linguístico em sincronias passadas. Mais uma vez, a questão que se impõe é a seguinte: os materiais didáticos de ensino de língua portuguesa acompanhariam o inovadorismo do imperativo abrasileirado como expressão da inserção do você no quadro pronominal do PB?

\section{As propostas dos livros didáticos de língua por- tuguesa: o que dizem sobre o modo imperativo?}

Considerando o fato de que o Programa Nacional do Livro Didático vem, desde 1985, se deixando evidenciar como um mecanismo endossado pelo MEC para licenciar o material didático que vigorará nas salas de aula brasileiras, acreditamos que se faça necessário analisar se os resultados das pesquisas linguísticas sobre o imperativo já alcançaram as aulas de línguas portuguesa através de sistematizações linguísticas coerentes em relação à realidade linguística do PB. Uma vez esclarecido que o critério para a seleção do material didático que embasa esta análise é a 
sua aprovação pelo PNLD, em suas versões de 2015 e 2018, elencamos quinze livros didáticos voltados para o Ensino Médio. No que se refere à análise orientada pelo PNLD 2015 selecionamos os seguintes títulos: Português: contexto, interlocução e sentido (ABAURRE et al., 2013), Lingua portuguesa (ALVES et al., 2013), Novas palavras (AMARAL et al., 2013), Ser protagonista: língua portuguesa (BARRETO et al., 2013), Português: vozes do mundo (CAMPOS et al., 2013), Viva português: Ensino Médio (CAMPOS et al., 2013), Português linguagens (CEREJA et al., 2013), Português: língua e cultura (FARACO, 2013), Língua portuguesa: linguagem e interação (FARACO et al., 2013) e Português linguagens em conexão (SETTE et al., 2013). Em relação ao PNLD 2018, voltamos o foco de análise para as seguintes obras didáticas: Veredas da Palavra (ALVES et al., 2016), Novas Palavras (AMARAL et al., 2016), Ser protagonista: língua portuguesa (BARRETO et al., 2016), Português contemporâneo: diálogo, reflexão e uso (CEREJA et al., 2016) e Português: trilhas e tramas (SETTE et al., 2016).

Com base no exame minucioso dos livros didáticos elencados, passamos à análise qualitativa da abordagem do imperativo, tendo em vista os seguintes critérios: (i) definição e estrutura morfológica; (ii) menção ao imperativo como um fenômeno variável e ao imperativo abrasileirado como uma especificidade do PB. Considerando esses critérios e os resultados dos trabalhos de Lopes (2012) e de Marcotulio (2016) sobre o fato de as inovações nos sistemas de pronomes pessoais e de possessivos não terem alcançado os livros didáticos, permite-nos hipotetizar que a expressão variável do imperativo de $2 \mathrm{SG}$ e o imperativo abrasileirado (PAREDES SILVA et al., 2000) também tenham sido ignorados nos materiais didáticos aprovados pelos PNLDs de 2015 e 2018.

\subsection{A abordagem do modo imperativo nas coleções di-} dáticas do ensino médio: definição e estrutura morfológica

Inicialmente, consideramos a definição e a estrutura morfológica do imperativo, observando, num segundo momento, não só considerações pontuais ou esparsas, mas também as propostas de atividades ou exercícios dos livros didáticos. Assim sendo, o levantamento das abordagens conceituais e estruturais do imperativo assumidas pelos livros didáticos conduziu-nos à síntese exposta no quadro 03 . 


\begin{tabular}{|c|c|c|c|}
\hline \multicolumn{4}{|c|}{ O IMPERATIVO NOS LIVROS DIDÁTICOS } \\
\hline $\begin{array}{l}\text { PROGRAMA NACIO- } \\
\text { NAL DO LIVRO DIDÁ- } \\
\text { TICO }\end{array}$ & AUTORES & $\begin{array}{l}\text { D E F I N I - } \\
\text { ÇÃO }\end{array}$ & $\begin{array}{l}\text { E S T R U- } \\
\text { T U R A } \\
\text { MORFO- } \\
\text { LÓGICA }\end{array}$ \\
\hline \multirow{10}{*}{ PNLD 2015} & ABAURRE ET AL. (2013) & $\checkmark$ & $\checkmark$ \\
\hline & ALVES ET AL. (2013) & $\checkmark$ & $\checkmark$ \\
\hline & AMARAL ET AL. (2013) & $\checkmark$ & $\checkmark$ \\
\hline & BARRETO ET AL. (2013) & $\checkmark$ & - \\
\hline & CAMPOS ET AL. ${ }^{1}$ (2013) & - & - \\
\hline & CAMPOS ET AL. ${ }^{2}$ (2013) & $\checkmark$ & $\checkmark$ \\
\hline & CEREJA ET AL. (2013) & $\checkmark$ & $\checkmark$ \\
\hline & FARACO (2013) & - & - \\
\hline & FARACO ET AL. (2013) & $\checkmark$ & - \\
\hline & SETTE ET AL. (2013) & $\checkmark$ & $\checkmark$ \\
\hline \multirow{5}{*}{ PNLD 2018} & ALVES ET AL. (2016) & $\checkmark$ & $\checkmark$ \\
\hline & AMARAL ET AL. (2016) & $\checkmark$ & $\checkmark$ \\
\hline & BARRETO ET AL. (2016) & $\checkmark$ & - \\
\hline & CEREJA ET AL. (2016) & $\checkmark$ & $\checkmark$ \\
\hline & SETTE ET AL. (2016) & $\checkmark$ & $\checkmark$ \\
\hline
\end{tabular}

Quadro 03: A definição e a estrutura morfológica do imperativo nos livros didáticos

De um modo geral, constatamos que os livros didáticos se preocupam não só em definir o modo imperativo, mas também em apresentar a sua estruturação morfológica. Apesar de o modo imperativo ter sido definido em treze materiais didáticos, dentre os quinze analisados, dois deles não definiriram o imperativo (CAMPOS et al. ${ }^{1}$, 2013; FARACO, 2013). Em relação à sua estruturação morfológica, observamos que, se, por um lado, dez livros mostraram-se atentos à descrição da morfologia das construções imperativas com formas de indicativo (imperativo verdadeiro) e formas de subjuntivo (imperativo supletivo), tão somente cinco materiais didáticos (BARRETO et al., 2013; BARRETO et al., 2016; CAMPOS et al. ${ }^{1}$, 2013; FARACO, 2013; FARACO et al., 2013), não abordaram a sua configuração formal, ainda que alguns dentre eles o tenham definido 
(BARRETO et al., 2013; FARACO et al., 2013; BARRETO et al., 2016). Considerando a peculiaridade da estrutura morfológica do imperativo afirmativo ativada a partir da perda do morfe [-s] para formas de $2 \mathrm{SG}$ (ama tu) e 2PL (amai vós) no presente do indicativo, acreditamos que se, por um lado, tais dados se mostram distantes daquilo que é normal na realidade linguística dos alunos do ensino médio no Brasil, por outro lado, provavelmente terão acesso a tais formas verbais imperativas através da leitura de textos literários ou textos históricos do português, o que justifica, pois, serem apresentados a tais evidências da norma-padrão também nas aulas de língua portuguesa.

No que se refere especificamente à definição do imperativo, os materiais didáticos interpretaram-no, de um modo geral, como o modo verbal (CEREJA, 2013, p. 137), "da ordem, do pedido e do conselho", definição calcada na tradição gramatical, (ROCHA LIMA [1972] 2010; CUNHA E CINTRA, [1985] 2007; BECHARA, [1961] 2009) e também reforçada pelos estudos linguísticos contemporâneos, tendo em vista o ato ilocutório diretivo (SEARLE, 1969 citado em FARIA 2006, p. 73-74) que lhe é inerente. Nos livros didáticos analisados, a definição do imperativo, de um modo geral, está contextualizadamente respaldada por situações discursivas reais de uso linguístico, consubstanciadas em propagandas publicitárias e tirinhas. No entanto, é, no mínimo, intrigante o fato de duas coleções didáticas (CAMPOS et al. ${ }^{1}, 2013$ e FARACO, 2013) não terem sistematizado definições do imperativo, ainda que tais coleções tenham sido interpretadas (Guia de livros didáticos PNLD 2015) como coleções que primam por embasar a apresentação dos tópicos linguísticos em situações concretas da língua em uso.

Ao abordarem, por exemplo, o gênero anúncio publicitário, gênero propício à ampla ocorrência desse modo verbal, CAMPOS et al. ${ }^{1}$ (2013, vol. 2, p. 208-213) abstiveram-se não só da definição, mas também da estrutura morfológica do imperativo. Por outro lado, na proposta de FARACO, em 2013, ainda que não tenhamos observado o imperativo sistematicamente descrito, constatamos ter havido o seu tratamento indireto não só através da caracterização da linguagem do texto publicitário em (08), mas também através da proposta de uma atividade, em (09), de pesquisa acerca do imperativo na gramática, ou seja, o livro didático dirige os alunos do ensino médio a buscarem informações sobre o imperativo nos compêndios gramaticais. 
(8) As linguagens da Publicidade (...) A linguagem verbal se caracteriza pelo uso de sentenças curtas e de expressões imperativas (experimente..., mude para..., não perca..., use já...). (FARACO, 2013, v. 3, p. 79-92)

(9) Atividades (...) 3. Vamos, agora, fazer uma visita à gramática. Novamente em pequenos grupos, localizem o capítulo que trata dos verbos. Em seguida, consultem os quadros das conjugações para observar como as formas são distribuídas em termos de pessoa, número, tempo e modo. Por fim, digam as formas correspondentes às seguintes descrições: (...) segunda pessoa do singular do imperativo afirmativo do verbo sentar (FARACO, 2013, p. 228.)

No que concerne especificamente à abordagem da configuração morfológica do imperativo, as coleções apresentaram, de um modo geral, as formas de imperativo verdadeiro (indicativo) e supletivo (subjuntivo) em consonância com os preceitos da tradição gramatical (ROCHA LIMA, [1972] 2010; CUNHA E CINTRA, [1985] 2007; BECHARA, [1961] 2009). Por outro lado, constatamos que cinco coleções didáticas (BARRETO et al., 2013; CAMPOS et al. ${ }^{1}$, 2013; FARACO, 2013; FARACO et al., 2013; BARRETO et al. 2016) não apresentaram a composição estrutural das construções imperativas. Esses dados nos permitem inferir que os alunos que estudaram português com base nesses livros didáticos não foram apresentados à confluência dos paradigmas verbais do presente dos modos indicativo e subjuntivo na formação do imperativo. Ainda que estejamos conscientes acerca do caráter extremamente artificial das formas verbais imperativas (regulares e irregulares) em relação especificamente à sua configuração formal, entendemos que a sua conjugação em conformidade com os parâmetros da norma-padrão passa também pela compreensão da sua estrutura morfológica.

\subsection{0 imperativo nas coleções didáticas do portu- guês: a rara menção a sua expressão variável.}

Considerando o potencial variável do imperativo no PB não só em relação às formas de imperativo verdadeiro (vem, faz, liga) e supletivo (venha, faça, ligue), mas também no que se refere às construções associadas ao indicativo em contexto de você-sujeito (Vem pra Caixa você também!), cf. já discutido por SCHERRE (2004, 2007, 2012), CARDOSO (2009), passamos à síntese da abordagem da expressão variável do imperativo concedida pelos livros didáticos analisados (quadro 04). 


\begin{tabular}{|c|c|c|}
\hline \multicolumn{3}{|c|}{ O IMPERATIVO NOS LIVROS DIDÁTICOS } \\
\hline $\begin{array}{c}\text { PROGRAMA } \\
\text { NACIONAL DO } \\
\text { LIVRO DIDÁTICO }\end{array}$ & AUTORES & $\begin{array}{l}\text { A MENÇÃO À } \\
\text { EXPRESSÃO } \\
\text { VARIÁVEL DO } \\
\text { IMPERATIVO } \\
(V E M / V E N H A) \\
(V E M V O C E \hat{)})\end{array}$ \\
\hline \multirow{10}{*}{ PNLD 2015} & ABAURRE ET AL. (2013) & - \\
\hline & ALVES ET AL. (2013) & $\checkmark$ \\
\hline & AMARAL ET AL. (2013) & - \\
\hline & BARRETO ET AL. (2013) & - \\
\hline & CAMPOS ET AL. ${ }^{1}$ (2013) & - \\
\hline & CAMPOS ET AL..$^{2}(2013)$ & $\checkmark$ \\
\hline & CEREJA ET AL. (2013) & - \\
\hline & FARACO (2013) & - \\
\hline & FARACO ET AL. (2013) & - \\
\hline & SETTE ET AL. (2013) & - \\
\hline \multirow{5}{*}{ PNLD 2018} & ALVES ET AL. (2016) & $\checkmark$ \\
\hline & AMARAL ET AL. (2016) & - \\
\hline & BARRETO ET AL. (2016) & - \\
\hline & CEREJA ET AL. (2016) & - \\
\hline & SETTE ET AL. (2016) & - \\
\hline
\end{tabular}

Quadro 04: A abordagem da expressão variável do imperativo nos livros didáticos.

Com base na análise do quadro 04, é possível evidenciarmos a postura conservadora dos materiais didáticos, ao desconsiderarem a variação nas construções imperativas de 2SG no PB. Dentre as quinze coleções didáticas analisadas contatamos que, em apenas três delas (ALVES et al., 2013, 2016; CAMPOS et al. ${ }^{2}, 2013$ ), houve a menção (direta e/ou indireta) ao potencial variável das construções imperativas no PB.

Dentre os três materiais didáticos que se mostraram inovadores, temos os livros didáticos assinados por ALVES $(2013,2016)$ como evidência de menção direta, à luz de Bagno (2011, p. 571), ao caráter variável do imperativo em relação aos eixos diatópico e discursivo. À título de exemplificação, os autores escolheram a sentença exposta em (10) através da 
qual observamos a alternância entre as formas do imperativo verdadeiro (entra tu) e supletivo (compre você) em uma mesma situação comunicativa propagandística explicitada através de uma placa.

(10) Entra aqui e compre alguma coisa. (ALVES et al., 2016, v.2, p.171.)

Ainda que a abordagem tenha sido indireta CAMPOS et al. ${ }^{2}$ (2013) o fizeram em relação imperativo como um fenômeno variável, ao apresentarem as evidências do imperativo abrasileirado em (11) e (12). No entanto, essas ocorrências foram interpretadas como específicas de situações comunicativas informais, perdendo assim a oportunidade de vincular a variação nas construções imperativas de $2 \mathrm{SG}$ ao processo de reorganização do quadro pronominal ativado pela inserção do você.

(11) Se a gripe te pegou logo ali na esquina, tome Coristina. (CAMPOS et al. ${ }^{2}, 2013$, v. 2, p. 248)

(12) Vem pra Caixa você também. Vem! (CAMPOS et al. ${ }^{2}$, v.2 , p. 248)

Em (11) e (12), as formas verbais imperativas tome (imperativo associado ao subjuntivo) e vem (imperativo associado ao indicativo) ilustraram o seu estatuto variável no PB. Entretanto, esses dados são interpretados, no livro didático, como escolhas discursivas orientadas pelo uso coloquial e sonoridade dos slogans propagandísticos amplamente divulgados no espaço geográfico brasileiro.

Ainda que as coleções didáticas tenham se mostrado, de um modo geral, distantes do imperativo como um fenômeno variável, algumas delas comprometeram-se tão somente com o potencial discursivo de tal modo verbal em relação às construções dos sentidos de ordem, apelo, pedido. Nesse sentido, os livros didáticos de Abaurre (2013), Faraco (2013) e Barreto (2013), ao elaborarem atividades didáticas, enfocaram, respectivamente, as intenções comunicativas específicas das construções imperativas, em (13) e (14); alguns slogans propagandísticos e, portanto, os contextos discursivos marcados pela função apelativa da linguagem, em (15), e, em uma tirinha protagonizada por Garfield, a expressão de uma ordem através de uma sentença imperativa (16).

(13) Não telefone todos os dias para seu amor. (ABAURRE et al., 2013, vol. 2, p. 279.)

(14) Seja humilde! (ABAURRE et al., 2013, vol. 2, p. 279.) 
(15) Seja um doador de órgãos. (FARACO et al., 2013, vol. 2, p. 294.)

(16) Não tire a tampa do pote! (BARRETO et al., 2013, vol. 2, p. 254.)

Por outro lado, como evidência do ápice do conservadorismo linguístico no que se refere ao imperativo, observamos o material didático elaborado por SETTE et al. (2013, vol. 2, p. 212). Nele, levantamos construções imperativas de tu-sujeito descontextualizadas em proposta de exercício de caráter estrutural, cf. ilustramos em (17) e (18).

(17) Crê em ti; mas nem sempre duvides dos outros.

(18) Abandona o que é teu e esquece-me.

As sentenças expostas em (17) e (18) evidenciam uma metodologia de aprendizagem orientada pela repetição de estruturas representativas da norma padrão independentemente da artificialidade de tais construções imperativas em contexto de tu-sujeito já que se mostram incorrespondentes ao que é usual no PB. Essas construções imperativas muito se assemelham às sentenças "Divide e sê vencedor", "Recebe com alegria os amigos que te visitam", "Frequenta os bons e serás bom (...)" e "Abri as portas à esperança, não deixeis entrar o desânimo" que, por sua vez, fomentaram as pesquisas de Scherre (2007) acerca da expressão gramatical variável do imperativo no PB. Para essas sentenças, a proposta do exercício estrutural e descontextualizado estabelecia que o aluno as passasse para a 2SG ou a 2PL de acordo com o caso (CEGALLA, 1991, p. 184 citado em SCHERRE 2007, p. 190).

Em síntese, em função das questões inicialmente propostas, é possível tecermos duas breves generalizações:

(I) De um modo geral, os livros didáticos analisados assumiram os preceitos da norma padrão relacionados ao imperativo não só no que se refere ao potencial ilocucionário resguardado em sua definição, mas também em relação à sua estrutura morfológica.

(II) O estatuto variável das construções imperativas de $2 \mathrm{SG}$ como consequência da reorganização do sistema pronominal do PB passou incólume nos livros didáticos em análise em virtude da formulação de observações superficiais acerca do uso de você-sujeito em construções de imperativo associadas ao indicativo.

Dessa maneira, constatamos que os resultados das pesquisas linguísticas sobre o imperativo gramatical do PB não ganharam espaço de reflexão sobre os usos linguísticos nas salas de aulas. 


\section{Considerações finais}

Os livros didáticos aprovados pelos PNLDs 2015 e 2018 mostraram-se, de um modo geral, afeitos tão somente à reprodução da norma padrão não só em relação à definição do imperativo, mas também no que se refere à sua configuração morfológica. Além disso, apesar de alguns materiais didáticos terem se voltado para a relevância do potencial ilocucionário do imperativo na construção do sentido do texto, prescindiram, por outro lado, do seu estatuto variável como uma legítima repercussão da reorganização do quadro pronominal acionada pela inserção do você (2SG).

Com base na análise de quinze materiais didáticos licenciados pelos respectivos PNLDs 2015 e 2018, constatamos uma real distância entre os resultados alcançados pelas pesquisas sociolinguísticas sobre o imperativo e a sua aplicação real na dinâmica do ensino de língua portuguesa para falantes nativos do PB. Nesse sentido, ratificamos um acentuado descompasso entre a pesquisa e o ensino também observado em relação às inovações dos quadros de pronomes pessoais e de possessivos do PB, discutido por Lopes (2012) e por Marcotulio et al. (2015), respectivamente.

Tendo em vista a busca pelo caráter inclusivo e identitário do ensino de língua portuguesa para falantes nativos do PB, defendemos ser imprescindível que os materiais didáticos se voltem para a exposição do alunado às estruturas que evidenciam a norma vernácula do $\mathrm{PB}$, reflexo de um sistema linguístico heterogêneo e variável, sem deixar, é claro, de apresentá-lo à norma-padrão. Os distintos saberes (normativo e vernacular) não se opõem exclusivamente (BARBOSA, 2007), mas se retroalimentam na dinâmica de aulas movidas pela reflexão sobre os usos linguísticos e os seus efeitos nas especificidades das situações comunicativas do PB. 


\section{THE IMPERATIVE IN PORTUGUESE COURSEBOOKS: THE DISTANCE BETWEEN RESEARCH AND EDUCATION}

\section{ABSTRACT}

The purpose of this article is to discuss the incorporation of linguistic research results on the variable expression of the imperative in Portuguese classes based on the analysis of high school coursebooks licensed by the Programa Nacional do Livro Didático (PNLD) in its versions of 2015 and 2018. We introduce the tradition perspective related to the imperative and some of the results of linguistic research on the variable statute of the grammatical imperative in Brazilian Portuguese. Thus, we corroborate that the approach of the imperative is given conservatively in accordance with the precepts of grammatical tradition, reinforcing only its illocutionary value for the construction of meaning.

KEYWORDS: grammatical imperative, pronominal variation, coursebooks.

\section{REFERÊNCIAS}

BARBOSA, Afrânio Gonçalves. Saberes gramaticais na escola. In VIEIRA, Silvia Rodrigues; BRANDÃO, Silvia Figueiredo. Ensino de Gramática: descrição e uso. São Paulo: Contexto, 2007. p. 31-54.

BECHARA, Evanildo. Moderna Gramática Portuguesa. Rio de Janeiro: Lucerna, 2009 [1961].

CEGALLA, Domingos Paschoal. Novíssima gramática da língua portuguesa. 34. ed. São Paulo: Nacional, 1991.

CARDOSO, Daisy Bárbara Borges. Variação e Mudança no Português Brasileiro: gênero e identidade. Tese (Doutorado apresentada ao Programa de Pós-Graduação da Universidade de Brasília) - UNB, Brasília, 2009.

CUNHA, Celso; CINTRA, Luís Filipe Lindley. Nova Gramática do Português Contemporâneo. Rio de Janeiro: Nova Fronteira, 2007 [1985]. 
CUNHA, Celso. A Questão da Norma culta. Rio de Janeiro: Tempo Brasileiro. 1985 .

DINIZ, Juliana Sander. A expressão variável do imperativo de $2^{a}$ pessoa do singular no português brasileiro: análise de cartas pessoais dos séculos XIX e XX. 2018. Dissertação (Mestrado em Estudos Linguísticos) - Universidade Federal de Minas Gerais, Belo Horizonte, 2018.

FARIA, Isabel Hub. O uso da linguagem. In: MATEUS, Maria Helena Mira; BRITO, Ana Maria; DUARTE, Inês; FARIA, Isabel Hub; FROTA, Sônia; MATOS, Gabriela; OLIVEIRA, Fátima; VIGÁRIO, Marina; VILLALVA, Alina. Gramática da língua portuguesa. Lisboa: Caminho, 2006. p.55-84.

LOPES, Célia Regina dos Santos. Pronomes pessoais. In: VIEIRA, Silvia Rodrigues; BRANDÃO, Silvia Figueiredo. Ensino de Gramática: descrição e uso. São Paulo: Contexto, 2007. p. 103-119.

LOPES, Célia Regina dos Santos. O quadro dos pronomes pessoais: descompasso entre pesquisa e ensino. In: ABREU, Maria Teresa Tedesco Vilardo; BERNARDO, Sandra Pereira. Matraga. vol. 19, n. 30. Rio de Janeiro: UERJ, jan./jun. 2012.

LOPES, Célia Regina dos Santos; CAVALCANTE, Sílvia Oliveira. A cronologia do voceamento no português brasileiro: expansão de você-sujeito e retenção do clítico-te. In: Linguística. 2012, v.25, p. 30- 65.

MINISTÉRIO DA EDUCAÇÃO. Guia de livros didáticos: PNLD 2015: língua portuguesa: ensino médio. - Brasília: Ministério da Educação, Secretaria de Educação Básica, 2014.

MARCOTULIO, Leonardo Lennertz; PINHEIRO, Igor Sanches; ASSIS, Dalila Mendes dos Santos de. A relação entre pesquisa e ensino: o quadro de possessivos do português. In: Cadernos de Letras da UFF Dossiê: Variação linguística e práticas pedagógicas. $\mathrm{n}^{\circ}$ 51, p. 239-260, 2015.

PAREDES SILVA, Vera Lucia; SANTOS, Gilda Moreira; RIBEIRO, Tatiana. Variação na $2^{\mathrm{a}}$ pessoa: o Pronome sujeito e a forma do imperativo. In: Gragoatá, UFF, v. 9, n. 9, p. 115-123, 2000.

ROCHA LIMA, Carlos Henrique da. Gramática normativa da língua portuguesa. Rio de Janeiro, José Olympio. 2011 [1972].

RUMEU, Márcia Cristina de Brito. Língua e sociedade: a história do pronome 'Você' no português brasileiro. Rio de Janeiro: Ítaca (FAPERJ), 2013.

RUMEU, Márcia Cristina de Brito. Formas variantes do imperativo de segunda pessoa nos séculos XIX e XX: a expressão do social. In: Signum: Estudos da Linguagem, 2016. v. 19, p. 310-341. 
SCHERRE, Maria Marta Pereira. Norma e uso - o imperativo no português brasileiro. In: DIETRICH, W.; NOLL, V. (Org.). O Português do Brasil - Perspectivas da pesquisa atual. Madrid/Frankfurt am Main: Iberoamericana - Vervuert, 2004, v. 1, p. 231-260.

SCHERRE, Maria Marta Pereira. Aspectos sincrônicos e diacrônicos do imperativo gramatical no Português Brasileiro. In. Alfa, São Paulo, 51 (1): 189-222. 2007. SCHERRE, Maria Marta Pereira. Padrões sociolinguísticos do português brasileiro: a importância da pesquisa variacionista. Tabuleiro de Letras, 2012. v. 04, p. 01-32.

SILVA, Erica Nascimento. Formas imperativas de segunda pessoa no português brasileiro. Tese (Doutorado em Língua Portuguesa) Faculdade de Letras, Universidade Federal do Rio de Janeiro, Rio de Janeiro, 2017.

\section{OBRAS CONSULTADAS:}

ABAURRE, Maria Luiza M.; ABAURRE, Maria Bernadete M.; PONTARA, Marcela. Português: contexto interlocução e sentido. 2. ed. São Paulo: Moderna, 2013.

ALVES, Roberta Hernandes; MARTIN, Vima Lia. Língua Portuguesa. Curitiba: Positivo, 2013.

ALVES, Roberta Hernandes; MARTIN, Vima Lia. Veredas da palavra. $1^{\mathrm{a}} \mathrm{ed}$ São Paulo: Ática, 2016.

AMARAL, Emília; PATROCINIO, Mauro Ferreira do; LEITE, Ricardo Silva; BARBOSA, Severino Antônio Moreira. Novas palavras. 2. ed. São Paulo: FTD, 2013.

AMARAL, Emília; PATROCINIO, Mauro Ferreira do; LEITE, Ricardo Silva; BARBOSA, Severino Antônio Moreira. Novas palavras. 3. ed. São Paulo: FTD, 2016.

BARRETO, Ricardo Gonçalves; MATINS, Matheus; GONÇALVES-SANTA BÁRBARA, Marianka; CLETO, Mirella L. V.; BERGAMIN, Cecília. PAIVA, Andressa Munique. Ser protagonista: língua portuguesa. 2 ed. São Paulo: Edições SM, 2013.

BARRETO, Ricardo Gonçalves; MATINS, Matheus; GONÇALVES-SANTA BÁRBARA, Marianka; CLETO, Mirella L. V.; BERGAMIN, Cecília. PAIVA, Andressa Munique. Ser protagonista: língua portuguesa. $3^{\mathrm{a}}$ ed. São Paulo: Edições SM: 2016. 
CAMPOS, Maria Tereza Arruda (Coord.). Português vozes do mundo: literatura, língua e produção de texto. São Paulo: Saraiva, 2013.

CAMPOS, Elizabeth Marques; CARDOSO, Paula Marques; ANDRADE, Sílvia Letícia. Viva português: Ensino Médio. São Paulo: Ática, 2013.

CEREJA, William Roberto; COCHAR, Thereza. Português linguagens, vol.2, 9. ed. São Paulo: Saraiva, 2013.

CEREJA, William Roberto; VIANNA, Carolina Assis Dias; CODENHOTO, Christiane Damien. Português contemporâneo: diálogo reflexão e uso. $1^{\mathrm{a}}$ ed. São Paulo: Saraiva, 2016.

FARACO, Carlos Alberto. Português língua e cultura: língua portuguesa. $3^{\mathrm{a}} \mathrm{ed}$. Curitiba, PR: Base Editorial, 2013.

FARACO, Carlos Emílio; MOURA, Francisco Marto de; MARUXO JÚNIOR, José Hamilton. Língua Portuguesa: linguagem e interação. $2^{\mathrm{a}}$ ed. - São Paulo: Ática, 2013.

SETTE, Maria das Graças Leão; TRAVALHA, Márcia Antônia; BARROS, Maria do Rozário Starling de. Português: linguagem e conexão. São Paulo: Leya, 2013. SETTE, Maria das Graças Leão; RIBEIRO, Ivone. TRAVALHA, Márcia; BARROS, STARLING, Rozário. Português: trilhas e tramas. $2^{a}$ ed. São Paulo: Leya, 2016.

Recebido: 30/04/2018

Aceito: 14/09/2018 